\title{
ORIGINAL ARTICLE - ENABLING TECHNOLOGIES Mapping of bionic array electric field focusing in plasmid DNA-based gene electrotransfer
}

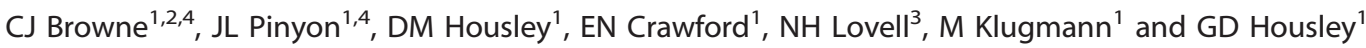

Molecular medicine through gene therapy is challenged to achieve targeted action. This is now possible utilizing bionic electrode arrays for focal delivery of naked (plasmid) DNA via gene electrotransfer. Here, we establish the properties of array-based electroporation affecting targeted gene delivery. An array with eight $300 \mu \mathrm{m}$ platinum ring electrodes configured as a cochlear implant bionic interface was used to transduce HEK293 cell monolayers with a plasmid-DNA green fluorescent protein (GFP) reporter gene construct. Electroporation parameters were pulse intensity, number, duration, separation and electrode configuration. The latter determined the shape of the electric fields, which were mapped using a voltage probe. Electrode array-based electroporation was found to require $\sim 100 \times$ lower applied voltages for cell transduction than conventional electroporation. This was found to be due to compression of the field lines orthogonal to the array. A circular area of GFP-positive cells was created when the electrodes were ganged together as four adjacent anodes and four cathodes, whereas alternating electrode polarity created a linear area of GFP-positive cells. The refinement of gene delivery parameters was validated in vivo in the guinea pig cochlea. These findings have significant clinical ramifications, where spatiotemporal control of gene expression can be predicted by manipulation of the electric field via current steering at a cellular level.

Gene Therapy (2016) 23, 369-379; doi:10.1038/gt.2016.8

\section{INTRODUCTION}

Electroporation is a technique widely used to deliver a variety of molecules, including drugs, proteins and nucleic acids, into cells. ${ }^{1-5}$ The underlying principle is that an electric field generated by a voltage pulse between two electrodes causes a transient dielectric breakdown of the plasma membrane of cells within the electric field, enabling molecules, such as negatively-charged DNA, to enter the cells. The process by which the cell membrane responds to the electric field, enabling DNA entry, is not well understood. ${ }^{4,6-9}$ DNA migration across the transiently permeabilized plasma membrane is not by simple diffusion, but may involve surface binding to a sustained 'electropore' compartment. ${ }^{10}$ Internalization is thought to occur via electrophoretically-driven movement of the DNA across the porated membrane, ${ }^{11,12}$ or sphingosine (lipid raft)/DNA complex formation, which mitigates the hydrophobic plasma membrane domains of the electroporated zone. ${ }^{13}$ It is clear that once inside the cell, the DNA is able to migrate to the nucleus. Circularized plasmid DNA remains extra-chromosomal and can drive sustained episomal expression, while linearized DNA may be integrated into the chromosomal DNA, enabling targeted genetic modifications.

The most common use for electroporation-based gene delivery is for molecular biology research, where simple plate electrodes within cuvettes enable routine transformation of electro-competent cells. High intensity electric field electroporation $\left(\sim 8000 \mathrm{~V} \mathrm{~cm}^{-1}\right)$ was first utilized for mammalian gene delivery in a suspended cell application. ${ }^{14}$ Electroporation-based gene delivery has subsequently been extended to in situ, ex vivo and in vivo applications with the development of specialized electroporation systems.
These electroporation systems include a variety of electrode designs and voltage pulse shaping as part of optimized electroporation parameters, along with custom electroporation solutions and electrodes. Key parameters include pulse intensity, pulse duration and repetition frequency. ${ }^{4,15-18}$ These systems have proved effective in facilitating research in a range of cell and tissue types, including developmental neurobiology studies, ${ }^{19-21}$ clinical electro-gene therapy and electrochemotherapy applications. ${ }^{22-24}$

Despite the wide range of electroporation applications both in vitro and in vivo, current technology has largely involved the application of electric fields utilizing conventional 'open-field' electrode configurations where two electrodes (typically plates or needles) are located either side of the target cells or tissue. This necessarily determines the electric field at the tissue level (macro domain), rather than considering electric fields at the cellular level (micro domain). A limited number of studies have investigated micro domain electroporation using glass microelectrodes with an external current return. ${ }^{25-27}$ Closely apposed electrodes (for example, created by ion deposition and photolithography) with sub-millimetre spacing for electroporation of immediately adjacent cells or cell processes within culture chambers have also been investigated. ${ }^{28,29}$ In such cases, the voltages required to achieve electroporation-based delivery of reporter gene constructs are considerably reduced over conventional electroporation modes (typically less than $10 \mathrm{~V}$ in comparison with several $100 \mathrm{~s} \mathrm{~V}$ or even $1000 \mathrm{~V}$ in conventional electroporation).

In a recent study, ${ }^{30}$ we reported the development of bionic electrode array-based electroporation (defined in that study as

\footnotetext{
${ }^{1}$ Translational Neuroscience Facility and Department of Physiology, School of Medical Sciences, UNSW Australia, Sydney, New South Wales, Australia; ${ }^{2}$ School of Science and Health, Western Sydney University, Sydney, New South Wales, Australia and ${ }^{3}$ Graduate School of Biomedical Engineering, UNSW Australia, Sydney, New South Wales, Australia.

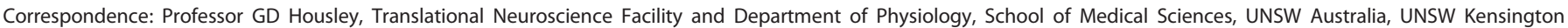
Campus, Sydney, 2052 New South Wales, Australia.

E-mail: g.housley@unsw.edu.au

${ }^{4}$ The authors wish it to be known that, in their opinion, the first two authors should be regarded as joint first authors.

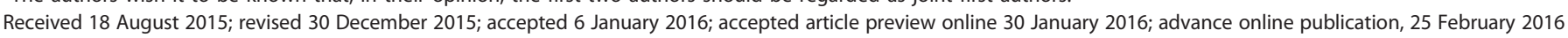


'close-field electroporation'), whereby a cochlear implant array comprising a linear series of $300 \mu \mathrm{m}$ diameter platinum ring electrodes was used to control electroporation within the cellular domain. Unlike macro domain electroporation, where cells are targeted between the electrodes through the shortest path for the current, array-based electroporation (micro domain) targets cells adjacent to the array of electrodes, where the electric field is shaped around the array by the combination of current sources and current returns with sub-millimetre separation between the anodes and the cathodes. In a pre-clinical proof of concept study, ${ }^{30}$ we utilized a linear 8-node cochlear implant electrode array that provided unanticipated efficiency and spatial control of delivery of a bicistronic neurotrophin and GFP expression cassette within the deafened guinea pig cochlea. The array-based electroporation gene therapy targeted mesenchymal cells adjacent to the array to express the neurotrophin alongside the GFP reporter, stimulating auditory nerve regeneration towards the electrodes. The result of this neural regeneration was a marked improvement in cochlear implant performance. To follow on from this discovery, here we describe, using a high-throughput HEK293 cell monolayer model, a systematic analysis of array-based electroporation parameters and measurement of electric field shaping, directed to optimizing control of gene delivery. These findings have significant ramifications for the translation of arraybased directed gene electrotransfer into the broad realm of gene therapy applications within the nervous system and beyond.

\section{RESULTS}

Validation of HEK293 cell monolayers as a model for evaluating array-based electroporation

Initial studies utilized the two bionic array electrode configurations adopted for ex vivo and in vivo gene delivery by array-based electroporation in the auditory nerve regeneration study by Pinyon et al. ${ }^{30}$ to confirm gene delivery was reproducible in a HEK293 cell monolayer. The pulse parameters were comparable to that previous study ( $40 \mathrm{~V}, 5$ pulses at 40 and $20 \mathrm{~ms}$ ). Array electrode configurations were as previously defined: The 'tandem' configuration utilized four consecutive electrodes ganged together as anodes and the other four electrodes were cathodes; an 'alternating' configuration had the anodes and cathodes alternating along the length of the array (Figure 1). Nuclearlocalized GFP expression by the HEK293 cells was imaged after $48 \mathrm{~h}(n=3$ per array configuration; Figure 2). These preliminary experiments demonstrated consistent cell transformation and showed that the array configuration affected the shape of the region of GFP-expressing cells. The use of the tandem configuration of electrodes provided a quasi-circular area of GFP-positive cells centred around the confluence between the four anodes and the four cathodes (Figure 2a). In contrast, the 'alternating' array configuration typically produced smaller areas of GFP-positive cells, with a linear pattern aligned with the longitudinal axis of the array (Figure 2b).

Effect of varying electrode configuration on array-based electroporation

To determine the impact of the electrode configuration on arraybased electroporation gene delivery, five different electrode configurations ('alternating'; 'tandem'; ' $1+2$ '; ' $1+5^{\prime} ;$ ' $1+8$ '; Figure 1) were compared using a common set of pulse parameters ( $40 \mathrm{~V}, 10$ pulses of $50 \mathrm{~ms}$ duration). There was a significant effect on transformation efficiency due to array configuration, with variation in the space between anode and cathode, and in the number and pattern of anodes and cathodes (one-way ranked analysis of variance (ANOVA), $P<0.001 ; n=4$ per configuration; Figure 3 ). All electrode configurations produced significant cell transduction compared with the control group (Table 1). The control group (no-electroporation) exhibited $0.8 \pm 0.8$ GFP-positive cells per coverslip. Within particular configurations, the number of transduced HEK293 cells was highly reproducible (varying from

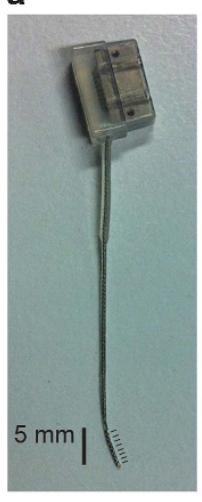

b

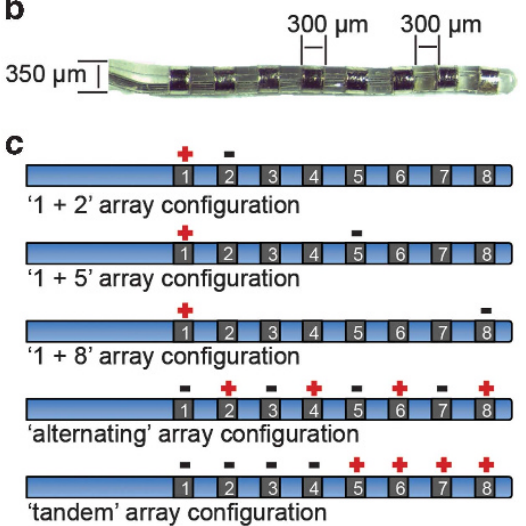

Figure 1. Electrode array configurations. (a) Photomicrograph of the 8-node linear (cochlear implant) electrode array (electrodes indicated by dashes). (b) Detail of the platinum ring electrodes. (c) Configurations of anodes (+) and cathodes (-) used to compare gene delivery efficiency.
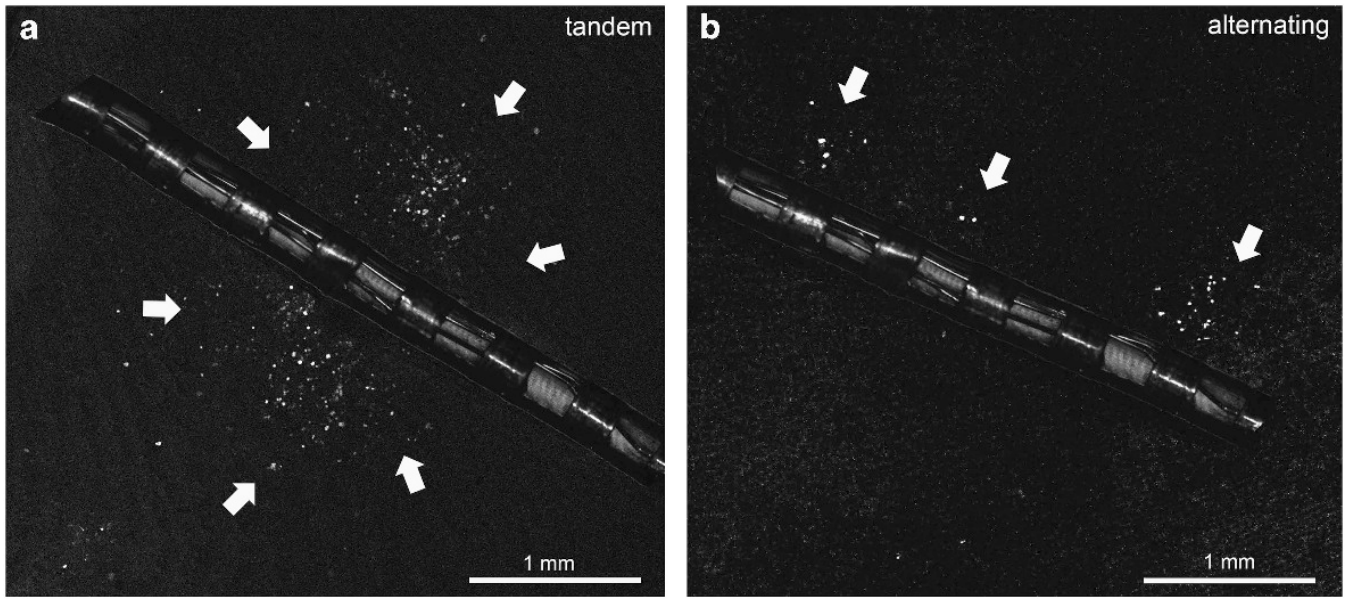

Figure 2. Transfected HEK293 cells expressed nuclear-localized GFP after array-based electroporation. (a) Tandem electrode array configuration produced a circular area of GFP-positive HEK293 cells around the centre of the array. (b) The 'alternating' array configuration produced elongated areas of transduced cells along the length of the array. Array shown as an overlay. 

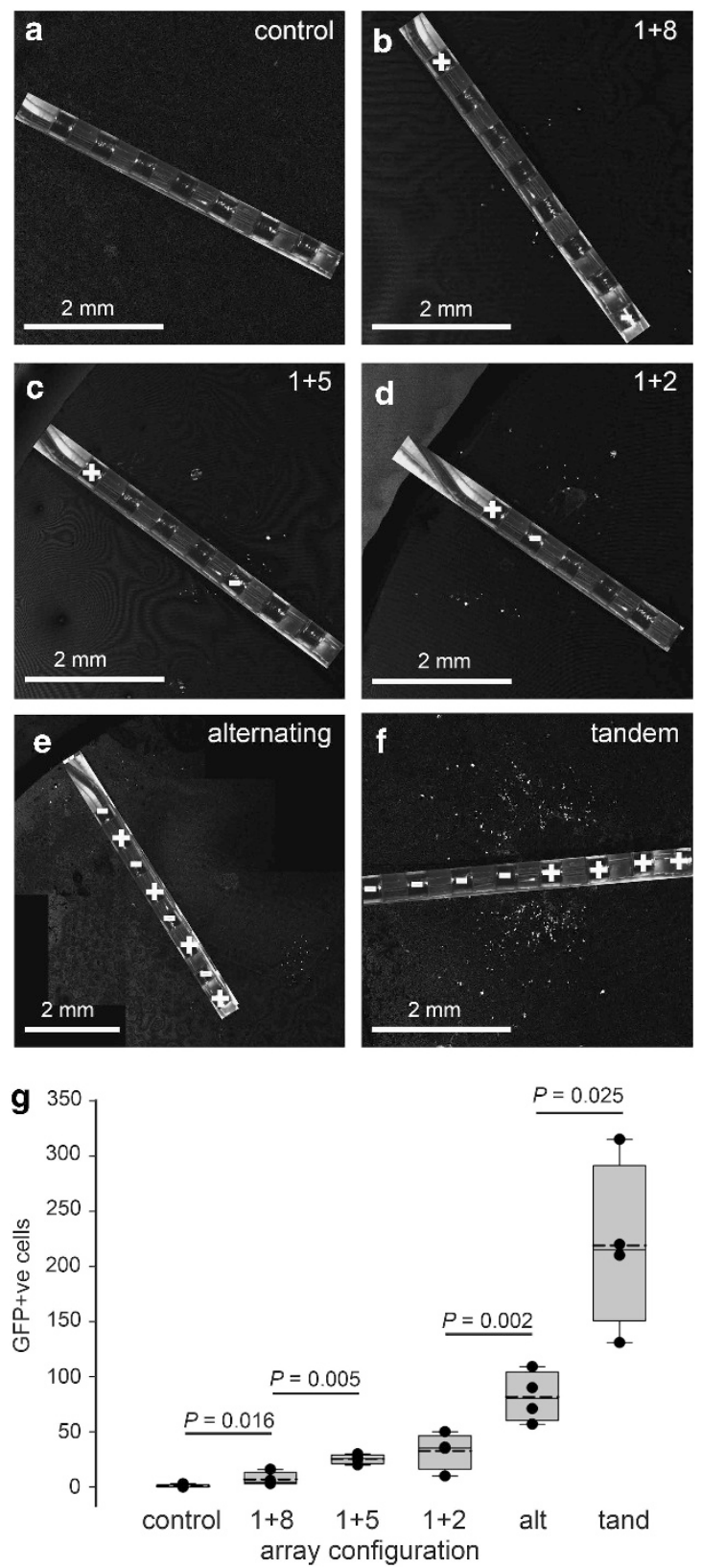

Figure 3. Effect of electrode array configuration on nuclear-localized GFP fluorescence in HEK293 cells indicating array-based electroporation gene delivery. (a) Control, plasmid DNA with the electrode array overlaying the cells, without electroporation; (b-f) examples of cell transduction areas for different electrode array configurations (indicated). (g) Summary showing statistical comparison (one-way ranked ANOVA, $n=4$ per configuration; alt, 'alternating'; tand, 'tandem'). All experiments utilized $40 \mathrm{~V}, 10$ pulses, $50 \mathrm{~ms}$ duration. Boxplots show median (line); mean (dashed line), 25 and $75 \%$ boundaries, overlaid with the data ( $n=4$ per group). Boxplot represents $25-75 \%$ distributions, bars indicate $95 \%$ confidence limits, and dashed lines are means.

$7.0 \pm 3.1$ (' $1+8$ ' configuration) to $219.0 \pm 37.7$ ('tandem'). The ' $1+2$ ' array configuration resulted in a circular area of cells $\sim 1 \mathrm{~mm}$ diameter, with the active electrodes at the centre (Figure 3d). As for the initial experiments, the 'alternating' electrode configuration produced a linear bias to the area of transfected cells, extending the length of the array $(\sim 5 \mathrm{~mm} ; 81.8 \pm 11.3$ GFP-positive cells; Figure $3 e)$. The ' $1+8$ ' and ' $1+5$ ' array configurations yielded smaller average numbers, which had a broad, low density distribution
Table 1. Statistical analysis for effect of electrode array configuration on transformation of HEK293 cells using electrode array-based plasmid DNA electrotransfer

\begin{tabular}{lrccc}
\hline Comparison & t-value & $\begin{array}{c}\text { Unadjusted } \\
\text { P-value }\end{array}$ & $\begin{array}{c}\text { Critical } \\
\text { level }\end{array}$ & Significance \\
\hline Tandem vs control & 14.014 & $<0.001$ & 0.003 & Yes \\
Tandem vs $1+8$ & 11.353 & $<0.001$ & 0.004 & Yes \\
Alt vs control & 11.176 & $<0.001$ & 0.004 & Yes \\
Alt vs $1+8$ & 8.515 & $<0.001$ & 0.004 & Yes \\
Tandem vs $1+5$ & 7.805 & $<0.001$ & 0.005 & Yes \\
$1+2$ vs control & 7.451 & $<0.001$ & 0.005 & Yes \\
Tandem vs $1+2$ & 6.564 & $<0.001$ & 0.006 & Yes \\
$1+5$ vs control & 6.209 & $<0.001$ & 0.006 & Yes \\
Alt vs $1+5$ & 4.967 & $<0.001$ & 0.007 & Yes \\
$1+2$ vs $1+8$ & 4.790 & $<0.001$ & 0.009 & Yes \\
Alt vs $1+2$ & 3.725 & 0.002 & 0.010 & Yes \\
$1+5$ vs $1+8$ & 3.548 & 0.002 & 0.013 & Yes \\
Tandem vs Alt & 2.838 & 0.011 & 0.017 & Yes \\
$1+8$ vs control & 2.661 & 0.016 & 0.025 & Yes \\
$1+2$ vs $1+5$ & 1.242 & 0.230 & 0.050 & No \\
\hline
\end{tabular}

Abbreviation: ANOVA, analysis of variance. Statistical analysis by one-way ranked ANOVA with Holm-Sidak multiple pairwise post hoc comparisons ( $n=4$ per group). Normality test passed $(P=0.053)$ and equal variance test passed $(P=0.718)$. Power of performed test with alpha 0.05:1.

(Figures $3 \mathrm{~b}$ and $\mathrm{c}$ ). The transfection efficiency with the tandem configuration was significantly higher than any of the other configurations (Figures $3 f$ and $g$; Table 1). As noted in the preliminary experiments (Figure 2a) using different pulse parameters, the pattern of transduction was circular in shape, centred around the mid-point of the array, which was the confluence point between the four anodes and the four cathodes. These data suggest that a key feature of array-based electroporation is submillimetre separation between the anode and cathode poles within the array; highlighting the difference between transduction using local electric field focusing and conventional 'open-field' electroporation, where the target region is located between separated electrodes.

\section{Electric field mapping}

Given the profound influence of electrode array configuration on the shape and density of the area of transformed cells, electric fields were mapped for all five electrode array configurations (Figures 4 and 5). The fields were sampled via the voltage probe with $\sim 300 \mu \mathrm{m}$ sampling separation parallel to the array and $\sim 1 \mathrm{~mm}$ orthogonal separation of the tracks. The voltage applied to the array was $4 \mathrm{~V}$, with quasi steady-state voltages at $100 \mathrm{~ms}$ measured at each position using all five configurations. This approached the maximum potential ( $500 \mathrm{mV}$ peak) that could be recorded via the isolated probe immediately adjacent to the array (Figures 4 and $5 \mathrm{a}$ ). The 'tandem' array exhibited the greatest change in electric field around the null position, tracking from the junction between the anodes and the cathodes (Figures $5 \mathrm{a}$ and $\mathrm{b}$ ). In contrast, despite utilizing an equivalent number of electrode elements, the 'alternating' array configuration had potentials that changed more gradually with distance from peak values close to electrode nodes, with the highest potentials around the tip of the array (Figure $5 \mathrm{c}$ ). The electric field around the arrays was closely correlated with the spatial mapping of GFP-reporter gene expression. Thus, the cell transduction was dependent upon the change of voltage across the cells, rather than the maximum voltage that could be measured within the sampled region around the array. In the 'tandem' configuration, the magnitude of the measured potentials was greatest at either end of the array, but the field was relatively uniform in that region. With regard to the electric field map for the 'tandem' configuration, the null point in the field migrates orthogonally to the array between electrodes 4 

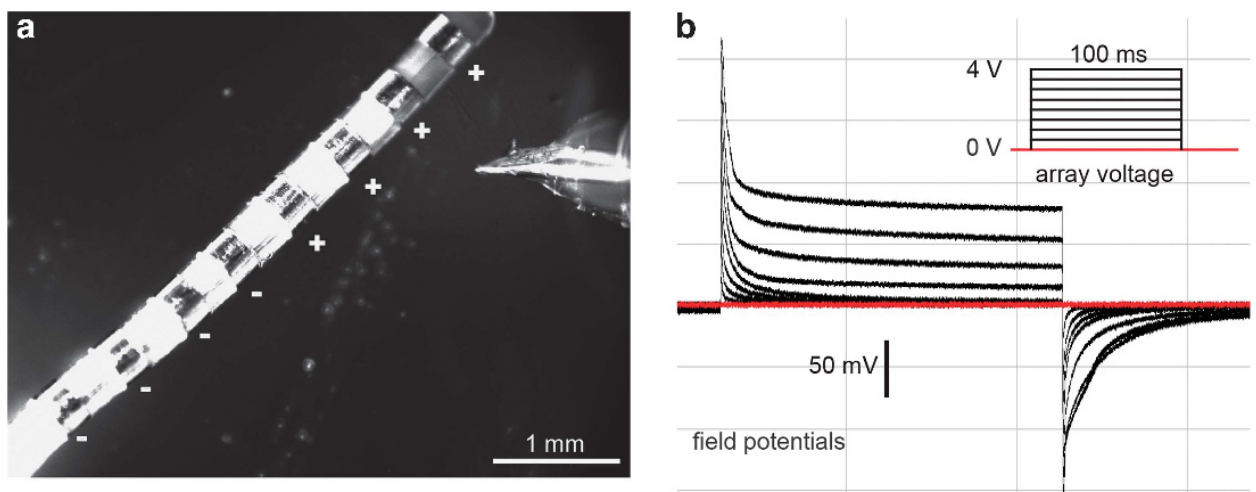

Figure 4. Electric field recordings. (a) Image of the 8-node linear (cochlear implant) electrode array with voltage-sensing electrode $\sim 500 \mu \mathrm{m}$ lateral to electrode 7. (b) Voltage measurements from the position shown in (a) with increasing voltage applied to the array in tandem configuration ( $100 \mathrm{~ms}$ pulses, stepped in $0.5 \mathrm{~V}$ increments to $4 \mathrm{~V}$ ). Inset shows the eight $0.5 \mathrm{~V}$ increments of applied voltage (range $0-4 \mathrm{~V}$ ). Sustained electric potentials are evident at $>2 \mathrm{~V}$ as the surface charging exceeds the faradaic capacity of the electrodes.

and 5 (Figure $5 \mathrm{~b}$ ). The field contour lines are steepest about this null region and are maintained in a spherical shape, which corresponds to the transduced cell map (Figures $2 a$ and 3f). In configurations ' $1+22^{\prime}, ' 1+5^{\prime}$ and ' $1+8$ ', as the distance separating the bipolar electrodes increased, the rate of decline in the field relative to the electrode nodes lessened (Figures $5 d-f$ ).

Although the voltages applied to the array to measure these voltages in the bath solution were below those required for arraybased gene electrotransfer (imposed by the upper voltage limit of the isolated voltage-following amplifier), nevertheless, estimates of field intensity required for gene delivery can be extrapolated from the linearity in growth of the sampled local voltage with increasing voltage applied to the electrode array (shown in Figure $4 b$ ). On this basis, from Figure $5 b$, the measured electric field $\sim 500 \mu \mathrm{m}$ lateral to the tandem array spanning electrode 2 to electrode 7 (defining the diameter of the area of GFP-positive cells in Figure 3f) was $114 \mu \mathrm{V} \mu \mathrm{m}^{-1}$ for $4 \mathrm{~V}$ applied. Thus, the electric field intensity that transduced the cells in Figure 2a (40 V applied) can be estimated at $\sim 2.17 \mathrm{mV} \mathrm{\mu m}^{-1}\left(\sim 22 \mathrm{~V} \mathrm{~cm}^{-1}\right.$; allowing for $\sim 2 \mathrm{~V}$ polarizing potential of the Pt. electrodes). The maximum electric field strength for the 'alternating' configuration was $\sim 100 \mu \mathrm{V} \mu \mathrm{m}^{-1}\left(1 \mathrm{~V} \mathrm{~cm}^{-1}\right)$ for the $4 \mathrm{~V}$ applied, around the apex of the array, but was more spatially limited $\left(\sim 1 / 3^{\text {rd }}\right.$ of the diameter of the tandem field), with multiple foci along the array. This is consistent with the linear rather than spherical area of GFPpositive cells achieved using this array configuration.

\section{Electric pulse parameters}

The effect of electric pulse parameters was systematically resolved utilizing the most efficient electrode configuration ('tandem').

Voltage amplitude. The numbers of transformed cells increased significantly with increasing pulse amplitude ( $40 \mathrm{~ms}$ duration, 10 pulses, 1 per second; Figure 6). The $40 \mathrm{~V}$ amplitude produced more than 40 times greater transformation than the $10 \mathrm{~V}$ amplitude $(196.7 \pm 18.5$ vs $5.9 \pm 1.1$ for $10 \mathrm{~V}$ and $32.3 \pm 6.3$ for $20 \mathrm{~V} ; n=9$ per group). No transformed cells were detected in the six control experiments (GFP plasmid, no-electroporation). The perimeters of the areas of GFP-positive HEK293 cells were determined for the $40 \mathrm{~V}$ group to estimate density $\left(29 \pm 2\right.$ cells per $\left.\mathrm{mm}^{2}, n=6\right)$. The overall density of HEK293 cells was established using 4',6-diamidino2-phenylindole (DAPI) fluorescence $\left(5097 \pm 333\right.$ cells per $\left.\mathrm{mm}^{2}\right)$. Hence, transduction efficiency was $\sim 0.6 \%$, which reflects a fall-off towards the perimeter.

Pulse number. Pulse number was a significant factor in cell transduction; at both 40 and $20 \mathrm{~V} \times 40$ ms pulses (two-way ranked
ANOVA, $P<0.001 ; n=6$ per group, except for 5 pulses $(n=9))$. At $40 \mathrm{~V}$, all pulse numbers $(1,3,5,10,20$ and 40) resulted in significantly greater transduction than the control (no-electroporation); ranked ANOVA, multiple comparisons vs control group (Holm-Sidak method; $P<0.001$ above 1 pulse; $P=0.0311$ pulse; $n=6$ per group, except for the 5 pulses group $(n=9)$ ) (Figure 7; Table 2), with 5, 10 and 20 pulses providing the maxima (range 147-170 cells) with no significant difference between these treatments (ANOVA, Holm-Sidak comparisons). At $20 \mathrm{~V}$, sets of 3, 5,10 and 20 pulses resulted in significantly greater transduction than the control (no-electroporation); ranked ANOVA, multiple comparisons vs control group (Holm-Sidak method; $P<0.003$; $n=6$ per group) (Figure 7; Table 2). The peak number of GFP-positive cells averaged 22 for $10 \mathrm{~V}$. There was a decline in transfected cell numbers at 40 pulses for both 20 and $40 \mathrm{~V}$. In addition, we observed propidium iodide fluorescence close to the electrode array position (Figure 8). This is a marker of cell permeability and cell toxicity, and the finding suggests that this roll-off in cell transformation is probably attributable to electrolytic and mechanical disruption of the cell monolayer associated with gassing, which was evident as fine bubbles on the surface of the electrodes after the electroporation sequence (evident in Figure 5a). On this basis, higher charge deliveries were not undertaken.

Pulse duration. Pulse duration experiments were undertaken with a single pulse or 5 pulses. All pulse duration experiments other than $0.1 \mathrm{~ms}$ for 1 pulse produced significant cell transduction $(P<0.004$; ranked ANOVA; Holm-Sidak multiple comparisons for 1 pulse; Mann-Whitney rank sum test for 5 pulses, $0.1 \mathrm{~ms}$; $P=0.026 ; n=6$ per group). Cell transduction was maximum at $100 \mathrm{~ms}$ pulse duration. Five pulses produced significantly greater transduction than 1 pulse (two-way ranked ANOVA, 10-400 ms indicating a significant interaction between pulse number and pulse duration; $P<0.001$; Figure 9; Table 3 ). With a single pulse, there was no difference between $40 \mathrm{~ms}$ ( $38.3 \pm 5.1$ cells), $100 \mathrm{~ms}$ $(51.7 \pm 7.8$ cells; $n=6)$ and $400 \mathrm{~ms}(49.2 \pm 6.9$ cells; $n=6)(P>0.05$; Holm-Sidak multiple comparisons), whereas with the 5-pulse treatment, $40 \mathrm{~ms}$ ( $147.2 \pm 12.4$ cells) and $100 \mathrm{~ms}$ ( $211.7 \pm 16.6$ cells) pulse durations produced significantly greater cell transformation than the other durations ( $P=0.003$ and $P<0.001$, respectively). The 400-ms pulse duration with 5 pulses resulted in a 5.5-fold decline from maximum ( $38.3 \pm 10.2$ cells; $n=6$ per group) $(P<0.001$; two-way ranked ANOVA, Holm-Sidak multiple comparisons), because of electrolytic toxicity.

Pulse separation. Separation of pulses between $50 \mathrm{~ms}$ and $1 \mathrm{~s}$ for $2 \times 40$ ms pulses, or $5 \times 40$ ms pulses, had no effect on the level of 
cell transduction ( 2 pulses, $P=0.255 ; 5$ pulses, $P=0.437$; two-way ranked ANOVA; Holm-Sidak multiple comparisons); $n=3$ per group (2P), $n=5$ per group (5P) (Figure 10).

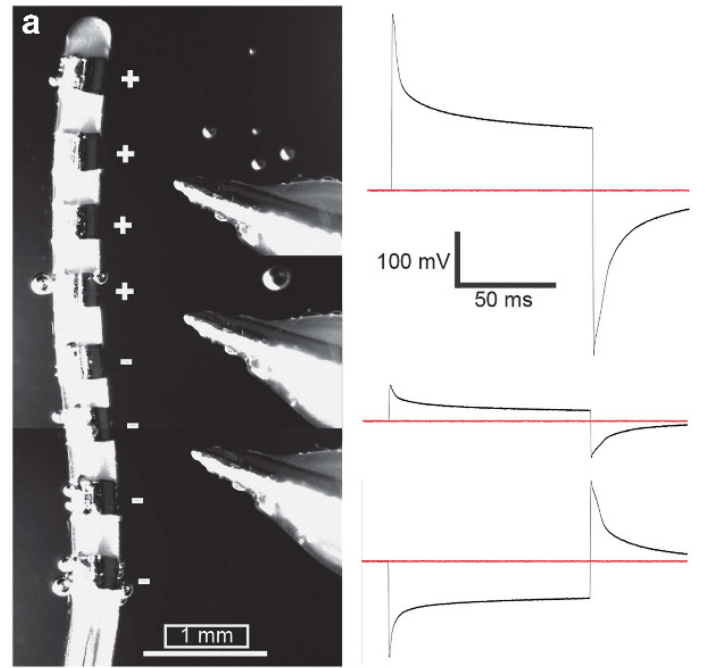

C

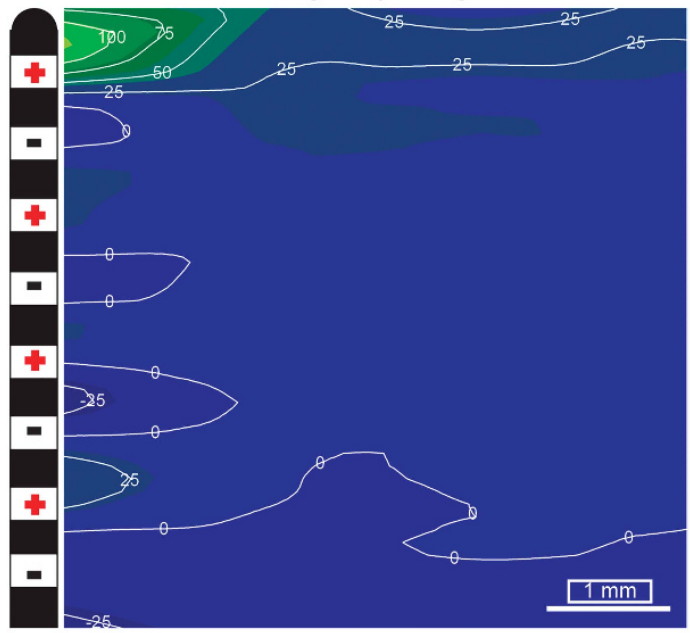

e

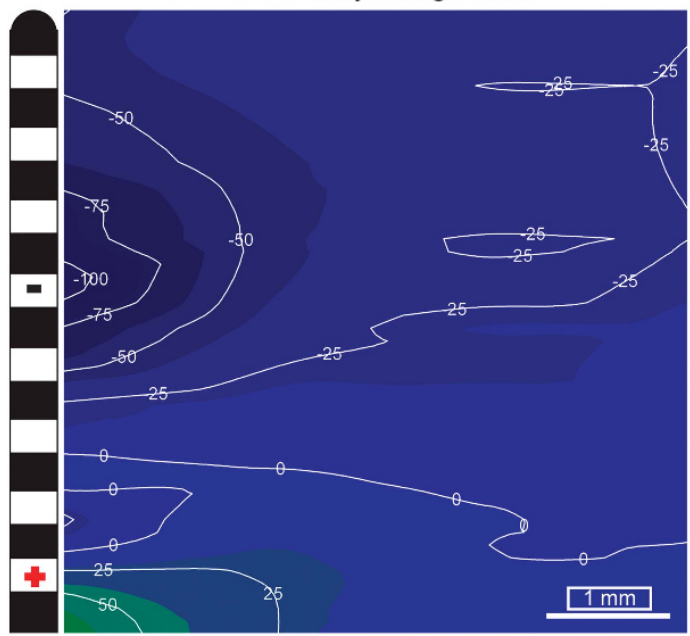

In vivo gene delivery

The refinement of the array-based electroporation parameters was validated in vivo, in the guinea pig cochlea, with $2 \times 100 \mathrm{~ms}$ pulses

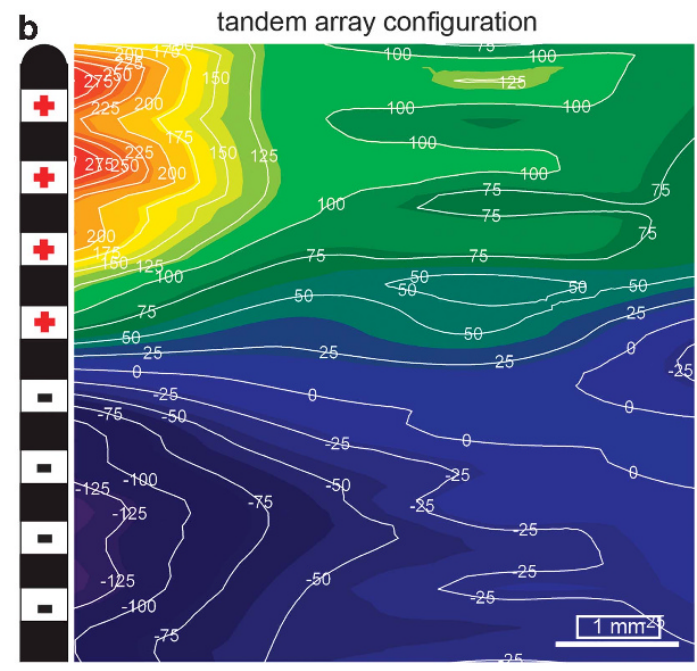

d

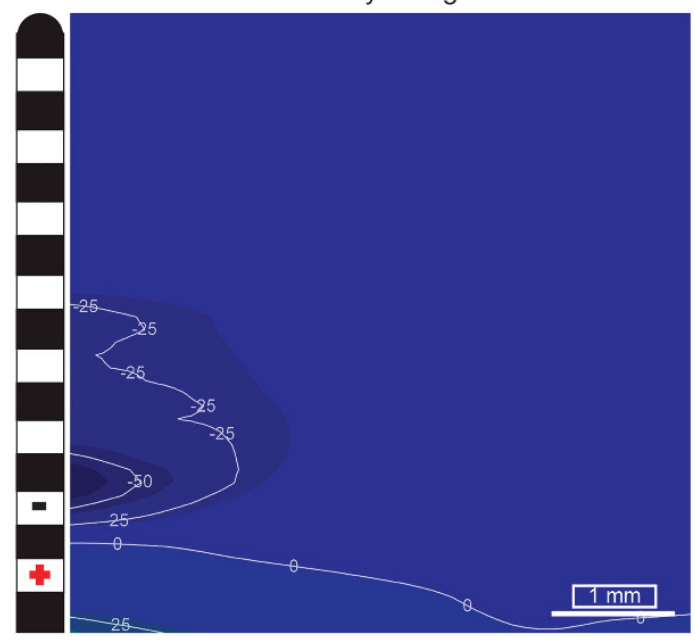

f

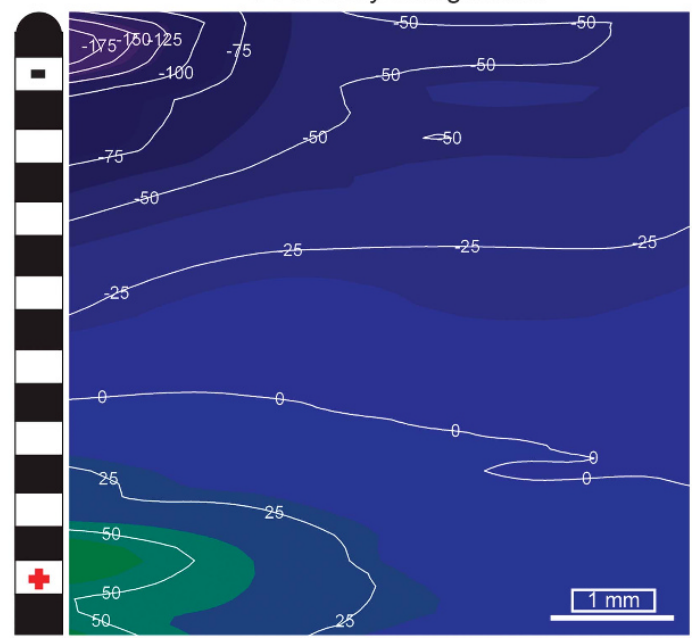

Figure 5. Variation in electric fields arising from electrode array configuration. (a) An example of three different recording positions for the tandem configuration. Note the reversal in polarity of the electric potentials (shown in $\mathrm{mV}$ ) moving from the apex to the base. (b-f) Electric field maps with isopotential contours for the five array configurations using $4 \mathrm{~V}$ applied, measured at $100 \mathrm{~ms}$, are shown. 


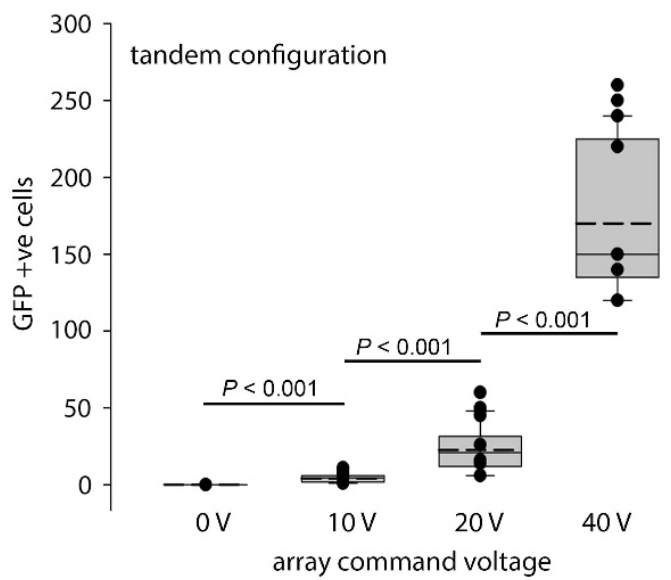

Figure 6. Effect of voltage amplitude on cell transformation with 'tandem' electrode configuration. Array-based electroporation gene delivery was delivered using 10 pulses at $40 \mathrm{~ms}$ duration, with varying voltage. Average number of transformed cells per experiment. $P$-values were determined by ranked ANOVA with Holm-Sidak test post hoc pairwise comparisons. All experiments utilized $40 \mathrm{~ms}$ duration, 10 pulses, 1 per second. Boxplots show median (line); mean (dashed line), 25 and $75 \%$ boundaries, overlaid with the data ( $n=9$ per group). Boxplot represents $25-75 \%$ distributions, bars indicate $95 \%$ confidence limits, and dashed lines are means.

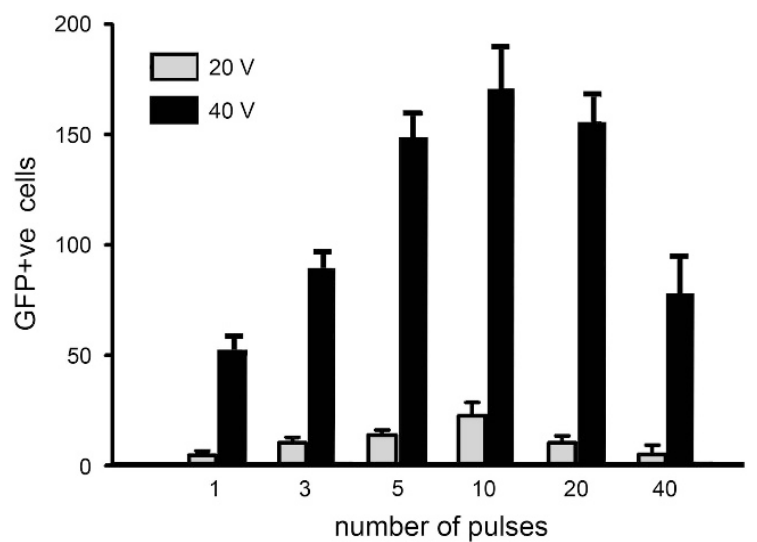

Figure 7. Effect of pulse number on transduction efficiency with 'tandem' electrode array configuration. Array-based electroporation gene delivery was delivered using $20 \mathrm{~V}$ and $40 \mathrm{~V}$ with $40 \mathrm{~ms}$ duration, varying pulse number, $n=6$ per group, except for 5 pulses $(n=9)$. Average number of transfected cells per experiment ( \pm s.e.m.). Statistical comparisons are provided in Table 2 based on two-way ranked ANOVA with Holm-Sidak test post hoc pairwise comparisons.

(10 V) resulting in GFP-positive mesenchymal cell nuclei consistently localized to the basal of the four turns of scala tympani (19.6 \pm 7.8 ; range $6-47$ cells (5/6 animals); no-electroporation controls showed 0 and 8 cells in two animals). This aligned closely with the placement of the electrode array (Figure 11). In one of the five GFP-positive test cochleae mesenchymal cells on scala vestibuli surface of Reissner's membrane were also labelled, as described previously. ${ }^{30}$ The region of GFP-positive cells spanned $\sim 2 \mathrm{~mm}$ along scala tympani, consistent with the focused gene delivery evident in the HEK293 cell monolayer experiments.

\section{DISCUSSION}

In our proof-of-principle study that demonstrated gene electrotransfer in the guinea-pig cochlea using a linear bionic electrode array $^{30}$ we showed that the charge delivery required to achieve efficient cell transduction was least when the array was configured for anodes and cathodes ganged together as bipoles ('tandem' configuration). The HEK293 cell monolayer is shown here to provide a high-throughput model for analysis of electrode arraybased gene delivery; validating and extending our earlier ex vivo and in vivo findings of the significance of array configuration. As shown by Pinyon et al., ${ }^{30}$ the 'tandem' configuration permitted significantly greater transduction efficiency compared with the equivalent number of electrodes wired in 'alternating' configuration. The current study also demonstrated that smaller bipolar electrode configurations were less efficient $(1+2,1+5,1+8)$. The reason that the 'tandem' array configuration shows unanticipated efficiency of cell transduction is attributed here to the geometry of electric field focusing (Figure 5). The 'tandem' array showed the highest electric field intensity adjacent to the electrodes compared with the other configurations. Given the spherical GFP-positive area of cells centred around the null point of the 'tandem' array (Figures 2a and 3f; orthogonal to the point between electrodes 4 and 5-Figure $5 \mathrm{~b}$ ), our data indicate that it is the change in electric potential across the cell (local electric field intensity), rather than the absolute step change in electric potential amplitude, that drives electroporation and DNA uptake. Thus, the tip region of the tandem array exhibited the largest local change in voltage, but this did not generate the most intense electric field (located lateral to the mid-region of the array). The cell distributions for the other array configurations showed similar association with the measured electric field intensity, and the drop off in number of GFP-positive cells in the $1+2>1+5>1$ +8 was correlated with the broadening in the electric field relative to the electrodes (Figures 5d-f). Electric field mapping using our low impedance probe had high spatial resolution, and depended upon isolation of the current stimulator and voltage probe and preclusion of ground loops. We also had the benefit of the quasi two-dimensional space provided by the HEK293 cell monolayer for stereotaxic manipulation of the probe census positions. An indirect approach for mapping electric field distribution in mouse tumour during electroporation has utilized magnetic resonance electric impedance tomography current density analysis with brief ( $100 \mu \mathrm{s})$ high field pulses between two needle electrodes. ${ }^{31}$ This study resolved local high voltages around each of the electrodes, with a minimum at the mid-point between the electrodes, resembling our voltage measurements for the $1+8$ bipolar array configuration (Figure 5f).

The present study also demonstrates that pulse duration is a key determinant of the cell transduction process, with an optimum around $100 \mathrm{~ms}$. Direct measurement of electric fields with increasing voltage steps shows some initial decay from peak due to the faradaic capacity of the platinum electrodes (Figure $4 \mathrm{~b}$ ). At voltages $>2 \mathrm{~V}$, sustained voltages are developed, approaching steady state by $\sim 100 \mathrm{~ms}$ (Figure $5 \mathrm{a}$ ). This is compatible with the concept that a sustained voltage gradient across the cells is required for efficient micro domain electroporation. The electric fields recorded here provide a relative representation of the fields that were generated, as the isolated voltage sensor was unsuitable for recording at the applied voltages associated with DNA uptake. However, above $2.5 \mathrm{~V}$ the voltages in the bath increased linearly with increasing voltage applied to the array, and at $4 \mathrm{~V}$ the maximum sustained potentials approached $\sim \pm 250 \mathrm{mV}$ immediately adjacent to the distal ends of the anode and cathode in the 'tandem' configuration. Extrapolating to a $20-\mathrm{V}$ pulse, which is efficient for gene delivery, the electric potential is likely to approach $\pm 2250 \mathrm{mV}$. In the 'tandem' array, the effective diameter of the area of GFP-positive cells was $\sim 50 \%$ of the array $(2.5 \mathrm{~mm})$, which indicates that the electric field would be $\sim 1125 \mathrm{mV}$ per $2.5 \mathrm{~mm}=4.5 \mathrm{~V} \mathrm{~cm}^{-1}$. Hence at the cellular level, the effective field is $\sim 450 \mu \mathrm{V} \mu \mathrm{m}^{-1}$.

Electroporation is still considered problematic for therapeutic gene delivery due to the low efficiency, trauma from placement of electrodes into tissues, and the typically high voltages that are 
Table 2. Statistical analysis for effect of pulse number on transformation of HEK293 cells using electrode array-based plasmid DNA electrotransfer

\begin{tabular}{|c|c|c|c|c|}
\hline & $\mathrm{t}$-value & Unadjusted P-value & Critical level & Significance \\
\hline \multicolumn{5}{|l|}{$40 \mathrm{~V}$ Comparisons } \\
\hline $40 \mathrm{~V}: 10$ pulses vs 1 pulse & 119.000 & $<0.001$ & 0.003 & Yes \\
\hline $40 \mathrm{~V}: 10$ pulses vs 40 pulses & 93.333 & $<0.001$ & 0.004 & Yes \\
\hline $40 \mathrm{~V}: 10$ pulses vs 3 pulses & 81.667 & $<0.001$ & 0.005 & Yes \\
\hline $40 \mathrm{~V}: 20$ pulses vs 40 pulses & 78.333 & $<0.001$ & 0.005 & Yes \\
\hline $40 \mathrm{~V}$ : 5 pulses vs 3 pulses & 58.889 & 0.004 & 0.007 & Yes \\
\hline $40 \mathrm{~V}: 3$ pulses vs 1 pulse & 37.333 & 0.079 & 0.009 & No \\
\hline $40 \mathrm{~V}: 40$ pulses vs 1 pulse & 25.667 & 0.221 & 0.010 & No \\
\hline $40 \mathrm{~V}: 10$ pulses vs 5 pulses & 22.778 & 0.234 & 0.013 & No \\
\hline $40 \mathrm{~V}: 10$ pulses vs 20 pulses & 15.000 & 0.471 & 0.017 & No \\
\hline $40 \mathrm{~V}: 3$ pulses vs 40 pulses & 11.667 & 0.575 & 0.025 & No \\
\hline $40 \mathrm{~V}: 20$ pulses vs 5 pulses & 7.778 & 0.682 & 0.050 & No \\
\hline $20 \mathrm{~V}$ : 5 pulses vs 40 pulses & 2.461 & 0.017 & 0.004 & No \\
\hline $20 \mathrm{~V}: 10$ pulses vs 3 pulses & 1.913 & 0.060 & 0.005 & No \\
\hline $20 \mathrm{~V}: 10$ pulses vs 20 pulses & 1.879 & 0.065 & 0.005 & No \\
\hline $20 \mathrm{~V}: 20$ pulses vs 1 pulse & 1.763 & 0.083 & 0.006 & No \\
\hline $20 \mathrm{~V}: 3$ pulses vs 1 pulse & 1.730 & 0.089 & 0.006 & No \\
\hline $20 \mathrm{~V}: 20$ pulses vs 40 pulses & 1.513 & 0.135 & 0.007 & No \\
\hline $20 \mathrm{~V}: 3$ pulses vs 40 pulses & 1.480 & 0.144 & 0.009 & No \\
\hline $20 \mathrm{~V}: 5$ pulses vs 3 pulses & 0.981 & 0.330 & 0.010 & No \\
\hline $20 \mathrm{~V}$ : 5 pulses vs 20 pulses & 0.948 & 0.347 & 0.013 & No \\
\hline $20 \mathrm{~V}$ : 10 pulses vs 5 pulses & 0.931 & 0.355 & 0.017 & No \\
\hline $20 \mathrm{~V}$ : 40 pulses vs 1 pulse & 0.249 & 0.804 & 0.025 & No \\
\hline $20 \mathrm{~V}$ : 20 pulses vs 3 pulses & 0.033 & 0.974 & 0.050 & No \\
\hline
\end{tabular}

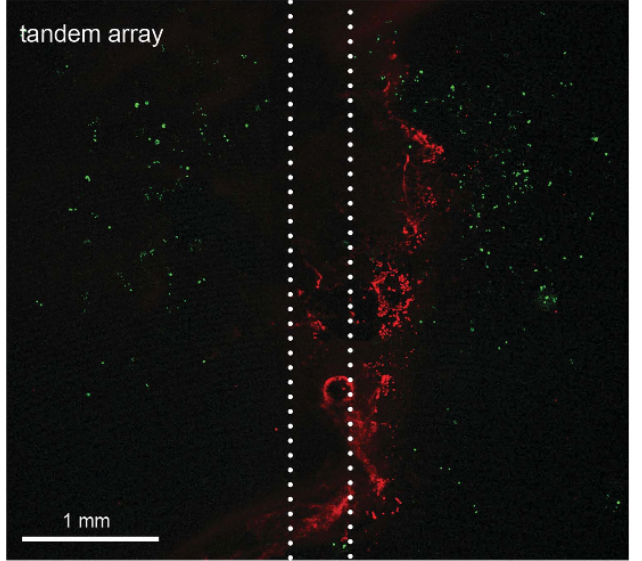

Figure 8. Effect of electrolytic toxicity and gassing detected using propidium iodide fluorescence (red) to label dead HEK293 cells $30 \mathrm{~min}$ after electroporation ( $40 \mathrm{~V}, 5 \times 40 \mathrm{~ms}$ pulses). The coverslip of cells was re-imaged after $48 \mathrm{~h}$ for nuclear-localized GFP (green). The absence of double labelled cells indicates that the delayed application of propidium iodide precluded uptake by viable electroporated cells.

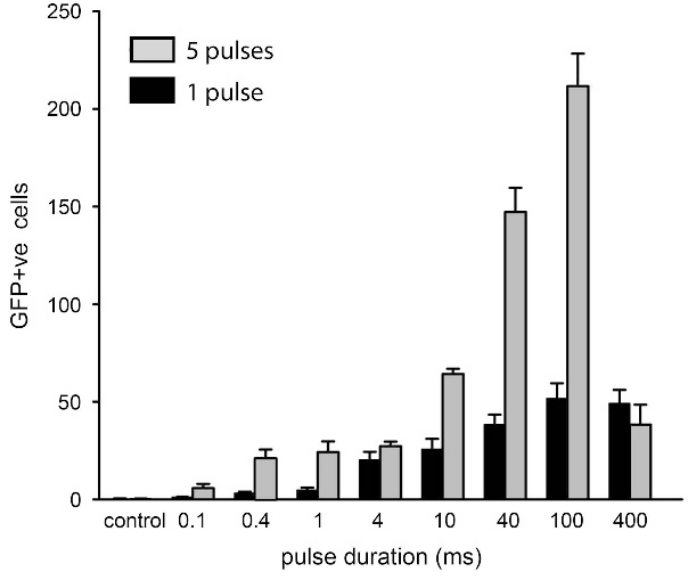

Figure 9. Effect of pulse duration on number of transfected cells with 1 or 5 pulses via 'tandem' electrode configuration, with $40 \mathrm{~V}$; $n=6$ per group. Mean ( \pm s.e.m.) number of transformed cells. Statistical comparisons are provided in Table 3 based on two-way ranked ANOVA with Holm-Sidak test post hoc pairwise comparisons. One pulse per second was delivered for the 5 pulses; noelectroporation control. 
Table 3. Statistical analysis for effect of pulse duration on transformation of HEK293 cells using electrode array-based plasmid DNA electrotransfer

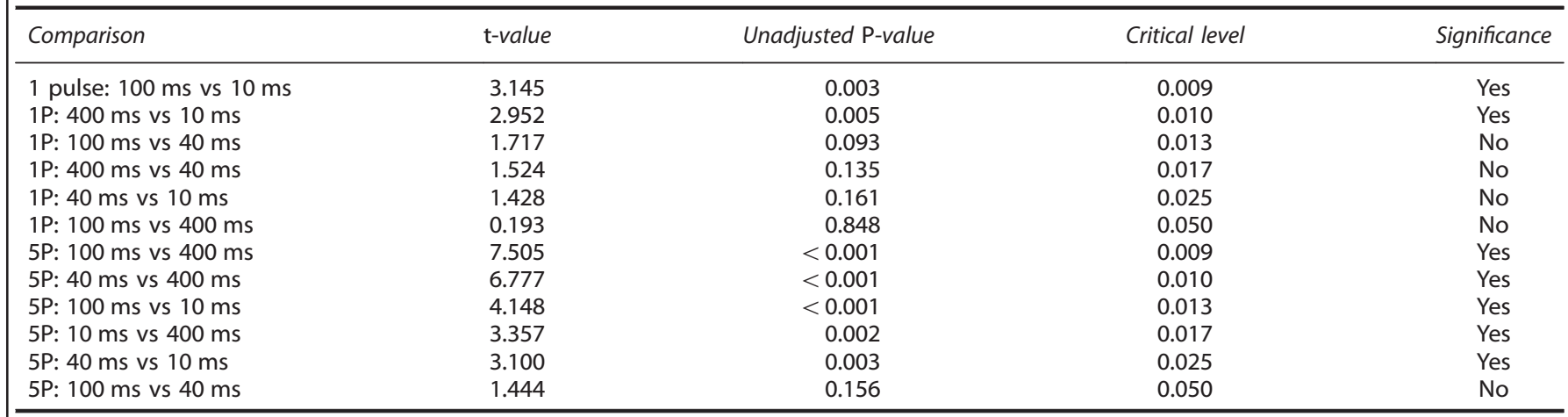

Abbreviation: ANOVA, analysis of variance. Statistical analysis by two-way ranked ANOVA with Holm-Sidak multiple pairwise post hoc comparisons. $40 \mathrm{~V}, 40 \mathrm{~ms}$ duration and with 1 pulse ( $n=6$ per group) or 5 pulses ( $n=6$ per group). Normality test passed $(P=0.297)$ and equal variance test passed $(P=0.326)$. Power of performed test with alpha 0.05:1.

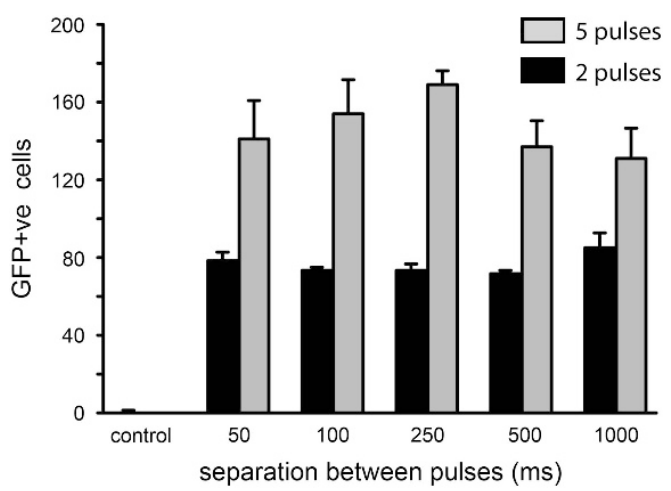

Figure 10. Effect of pulse separation on number of transformed cells with 2 ( $n=3$ per group) or 5 pulses ( $n=5$ per group) via 'tandem' electrode configuration, with $40 \mathrm{~V}$ pulses $40 \mathrm{~ms}$ in length and varying pulse separation. Mean ( \pm s.e.m.) number of transformed cells per experiment. Control; no-electroporation.

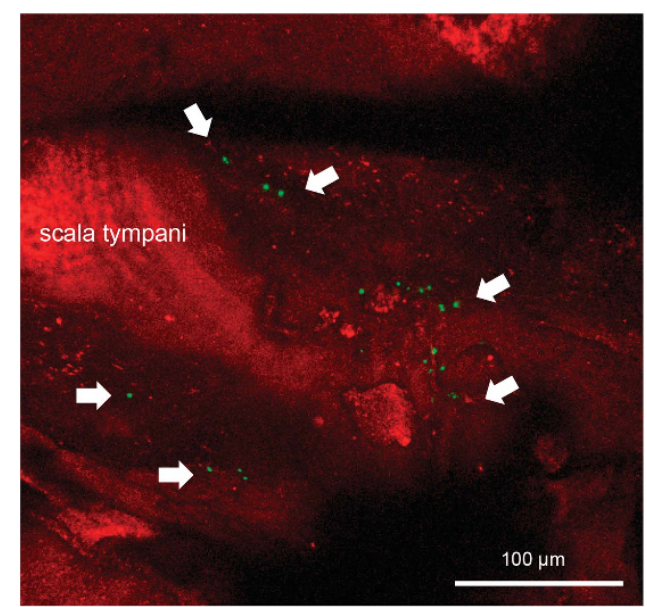

Figure 11. In vivo bionic array-based gene delivery validated in the guinea pig cochlea with nuclear-localized GFP in an area of mesenchymal cells (arrows) lining the wall of scala tympani in the basal turn (at 1 week); corresponding to the placement of the electrode array ('tandem' configuration; $2 \times 100 \mathrm{~ms}$ pulses at $10 \mathrm{~V}$ ).

required to enable DNA uptake. This can be perceived as a noxious stimulus, affecting the target organs and tissues, and may also impact on DNA stability. ${ }^{23,32}$ Study of the electroporation process at the single cell level has revealed that the transfection efficiency follows a different relationship to the electroporation efficiency with regard to the electric fields. Faurie et al. ${ }^{6}$ demonstrated using suspended Chinese hamster ovary cells that field strengths of $200 \mathrm{~V} \mathrm{~cm}^{-1}$ were sufficient for electroporation, but $400 \mathrm{~V} \mathrm{~cm}^{-1}$ was required for transfection based on expression of a reporter transgene. Similarly, Zhou et al. ${ }^{33}$ utilized $400 \mathrm{~V} \mathrm{~cm}^{-1}$ for macro domain electroporation of HEK293 cells ( $160 \mathrm{~V}$ between electrodes in a cuvette with a 4-mm gap). A study of DNA uptake into skeletal muscle showed benefit from a combination of short duration $(100 \mu \mathrm{s})$ 'high voltage' $\left(800 \mathrm{~V} \mathrm{~cm}^{-1}\right)$ and longer duration $(100 \mathrm{~ms})$ 'low voltage' $\left(8 \mathrm{~V} \mathrm{~cm}^{-1}\right)$ pulses to respectively permeablize and facilitate electrophoresis of the DNA across the plasma membrane. ${ }^{1}$ Studies using fluorescently-labelled DNA indicate that while the cells are permeabilized on both sides across the electric field, the (TOTO-1 labelled) plasmid-DNA only entered the cells on the cathode side. ${ }^{4,6}$ The permeabilization of the cell membrane occurs in the short time domain of the voltage pulses (typically in the $\mu s-m s$ range), while recovery of cell integrity occurs over minutes. ${ }^{34}$ This is consistent with our propidium iodide fluorescence imaging, which was performed $30 \mathrm{~min}$ after electroporation and indicated that membrane integrity was restored in the transduced cells. Pulse amplitude affects the rate at which the cell membrane becomes permeable and the area of the membrane that is electroporated; pulse duration and pulse number affect the degree of permeabilization. ${ }^{4,34}$ The permeabilization process depends upon the electric field causing charge redistribution on the cell membrane that occurs faster than the capacitance time constant of the cell. Thus, cell geometry is crucial, with mammalian cells requiring lower voltages than the smaller bacterial cells. In any case, it has been suggested that the applied voltages need to cause transmembrane potentials of $\sim 200 \mathrm{mV}$ or more for electroporation gene delivery. ${ }^{34}$ To achieve such a transient change in transmembrane potential, typically high field strengths are required in the macro domain for cell suspensions and tissue transfection (for example, $\sim 1.2 \mathrm{kV} \mathrm{cm}^{-1}$, equivalent to $480 \mathrm{~V}$ with a $4 \mathrm{~mm}$ electrode gap ${ }^{34}$ ). Our current data indicate that the electric potential required outside the cells for electroporation and gene delivery can be achieved using applied voltages $\sim 100$ times less with array-based micro domain electroporation than those required for macro domain electroporation. This is consistent with the reduction in applied voltages reported for electrotransfer of DNA in chick embyro neurodevelopment studies with very closely apposed electrode pairs $(1 \mathrm{~mm}$ exposure, $4 \mathrm{~mm}$ separation, $3-5 \times 50 \mathrm{~ms}$ pulses at $25 \mathrm{~V})_{i}{ }^{19}$ approximating our micro domain $1+5$ array configuration. Our electric potential measurements show that the electric field compression, and hence electrotransfer, increases as the anode and cathode separation is minimized within the bionic array. 
Clinical measures that utilize implantable bionic prostheses such as cochlear implants and deep brain stimulators are by their nature amenable to the incorporation of complementary gene therapy via array-based electrotransfer. This method of gene delivery, validated in our original proof of principle experiments showing cochlear implant array-mediated delivery of the BDNFGFP gene cassette to the guinea-pig cochlea ${ }^{30}$ and refined here in vivo using just two $100 \mathrm{~ms}$ pulses at $10 \mathrm{~V}$ applied in the 'tandem' configuration, has the potential to provide a much safer and more targeted genetic enhancement than can currently be provided by other approaches, such as viral vectors or lipofection. The more immediate translation of electrode arraybased gene delivery would be via adaptation of existing bionic neural prosthesis, while future development of custom electrode arrays may extend the control of the shape and extent of the transduced area of cells which the current study demonstrates as a proof of principle. Bionic array-based gene electrotransfer provides an imminently controllable targeting of gene delivery using naked DNA, which is not achievable with other processes. The utility of combining directed gene delivery that enhances the neural interface-such as demonstrated by Pinyon et al., ${ }^{30}$ for neurotrophin-driven repair of the auditory nerve, may complement current (bionic) approaches and improve outcomes for patients. For example, the spatiotemporal control of gene delivery achievable with this micro domain array-based electroporation may offer a refinement of possible viral vector-based treatment of Parkinson's disease by gene therapy targeting neurochemical modulation of the subthalamic nucleus with a glutamic acid decarboxylase (GAD65) DNA construct. ${ }^{35}$ Electroporation of naked DNA gene cassettes also has clear advantages over other gene delivery technologies due to the lack of inflammatory responses compared with lipofection ${ }^{33}$ or viral vectors (particularly adenovirus) ${ }^{36}$ and because the size of the plasmid DNA cassettes is relatively unconstrained.

Overall, the study demonstrated remarkable control of cell transformation with naked DNA was achievable-with 'dial-up' predictability in localized gene delivery and consequent expression of the gene construct being achieved. This evident control of the site and extent of gene expression is a key element in safe and effective gene therapy approaches for treatments of brain disorders in particular, where therapeutic action is required at specific sites. With regard to potential tissue damage, the highest charge deliveries resulted in electrolytic action and significant physical disruption to the HEK293 cell monolayer due to gassing. This is a result of the Faradaic current limits of the platinum electrodes, we previously estimated as a minimum effective charge delivery of $\sim 25 \mathrm{mC} \mathrm{cm}^{-2,30}$ where the pseudocapacity of the platinum electrodes for reversible charge delivery is $\sim 210 \mu \mathrm{C} \mathrm{cm}^{-2.37}$ Thus even with inert electrodes such as platinum, possible electrochemical damage to cells may be a factor when relatively long pulse durations, high voltages and long pulse trains are utilized, with potential changes in $\mathrm{pH}$ arising from production of $\mathrm{H}^{+}$at the anode and $\mathrm{O}_{2}$ or $\mathrm{Cl}_{2}$ gas, and $\mathrm{OH}^{-}$production at the cathode from reduction of water. ${ }^{38}$ Tissue (Joule) heating may also be associated with electroporation and both raise cell temperature and potentially destabilize DNA. ${ }^{39}$ Translation of bionic array-based gene therapy applications would need to be achieved below charge delivery levels that could damage cells in the neighbourhood of the electrode array. Such an outcome has been demonstrated in vivo, in the case of BDNF gene cassette delivery in the guinea-pig cochlea. ${ }^{30}$ In the cochlea, the physical dimensions of the fluid space (scala tympani) where cochlear implants are inserted closely match the spatial dimensions for effective electrode array-based gene delivery. The mapping of the electric fields around the cochlear implant shows close overlap between the area of GFP transduction in HEK293 monolayers and the site of transfection within the perilymphatic compartments of the cochlea, in which the basal turn of the guinea pig is around $2 \mathrm{~mm}$ in diameter. That study also showed that transduction of a few hundred (mesenchymal) cells with a neurotrophin gene cassette was sufficient to stimulate neural regeneration. Thus, intrinsic therapeutic peptide synthesis and release by limited number of cells achieved by array-based plasmid DNA electrotransfer may have strategic therapeutic advantages over conventional drug delivery or broader gene delivery using alternative approaches.

\section{CONCLUSION}

The current study utilized a high-throughput model, the HEK293 cell monolayer, to characterize the parameters contributing to the newly identified process of electrode array-based gene delivery. The study showed that the shaping of the electric field around a linear array of closely spaced sub-millimetre sized electrodes contiguous with the target cell population was the key element in efficient cell transduction. The potential difference across the cell, an approximate estimate of local electric field to which the cell is exposed, was the principal factor in transduction, rather than the absolute change in voltage during the electric pulse. Pulse duration and number of pulses also contributed to the transduction efficiency. The configuration of the array of electrodes, and hence the shape of the resulting electric field, provided control over the shape of the area of transduced cells. In combination, these factors lend 'dial-up' control of electrode array-based gene electrotransfer.

\section{MATERIALS AND METHODS}

\section{DNA plasmid}

The experiments utilized a plasmid (7481 bp) encoding the humanized renilla green fluorescent protein (GFP) reporter fused to a nuclear localization signal. The reporter was driven by the cytomegalovirus early enhancer element, chicken $\beta$-actin (CAG) hybrid promoter. The woodchuck post-transcriptional regulatory element was added downstream from the open reading frame. For electrode array-based electrotransfer, the plasmid was purified from E. coli using a Plasmid Maxi Kit (Qiagen, Melbourne, VIC, Australia) and resuspended at $2 \mu \mathrm{g} \mathrm{\mu l} \mathrm{I}^{-1}$ in $50 \mathrm{~mm}$ Trisbuffered saline ( $\mathrm{pH}$ 7.4).

\section{Cell culture}

The human embryonic kidney (HEK293) cell line (Thermo Fisher Scientific, Melbourne, VIC, Australia) was used as the substrate for evaluation of electrode array-based gene delivery. The cells were maintained in Dulbecco's Modified Eagle's Medium supplemented with 10\% heatinactivated fetal bovine serum (HI-FBS, Thermo Fisher Scientific), 1\% Penicillin/Streptomycin mix (Thermo Fisher Scientific), 1\% non-essential amino-acids (Thermo Fisher Scientific). Cells were split the day before electroporation and applied to glass coverslips that had the array placement marked on the underside ( $80 \%$ confluence). Cells were maintained in an incubator $\left(37^{\circ} \mathrm{C}, 5 \% \mathrm{CO}_{2}\right)$.

\section{Array-based electroporation}

Electroporation used a CUY21 Square Wave Electroporator (NepaGene), connected to a linear 8-node cochlear implant array (Cochlear Ltd, Sydney, NSW, Australia; part no. Z60276; after ${ }^{30}$ ). The array consisted of eight platinum ring electrodes each $350 \mu \mathrm{m}$ diameter, of $300 \mu \mathrm{m}$ width, separated by a $300 \mu \mathrm{m}$ gap. To electroporate the HEK293 cells, the coverslip with the cells was removed from the cell culture well and placed on a raised flat surface. The electrode array was lowered onto the coverslip, and the DNA was evenly applied over the array $(20 \mu \mathrm{l})$. Electroporation was then initiated using particular electrode configurations and electroporation parameters. Immediately after electroporation, coverslips were placed in a humidity chamber for 2 min before returning to fresh, pre-warmed media in the incubator.

\section{Imaging}

At $48 \mathrm{~h}$ post electroporation, HEK293 cell monolayers were fixed with $4 \%$ paraformaldehyde for $30 \mathrm{~min}$ and then gently washed with phosphate- 
buffered saline for $15 \mathrm{~min}$. The coverslips with the transformed cells were mounted on glass slides using Prolong Gold mounting medium containing 4',6-diamidino-2-phenylindole (DAPI) (Thermo Fisher Scientific). The slides were left to cure at room temperature for $24 \mathrm{~h}$ in the dark before storage at $4{ }^{\circ} \mathrm{C}$ until imaging. The areas of transformed HEK293 cells were imaged using a $\times 2.5$ objective on a confocal laser scanning microscope (Zeiss LSM 710; Carl Zeiss Pty Ltd, Sydney, NSW, Australia, argon ion laser; $488 \mathrm{~nm}$ excitation; 493-598 $\mathrm{nm}$ emission). Transfected cells expressing GFP were manually counted from the images.

Effect of electrode array configuration on gene electrotransfer

The electrodes within the array were configured as anodes and cathodes as follows (Figure 1): 1+2 (a single anode and a single cathode with $300 \mu \mathrm{m}$ separation), $1+5$ (a single anode and a single cathode with $2.45 \mathrm{~mm}$ separation), 1+8 (a single anode and a single cathode with $4.55 \mathrm{~mm}$ separation), 'tandem' (four juxtaposed ganged cathodes, then four ganged anodes, all elements with $300 \mu \mathrm{m}$ separation; total length $5.4 \mathrm{~mm}$ ) and 'alternating' (alternating cathodes and anodes with $300 \mu \mathrm{m}$ separation; total length $5.4 \mathrm{~mm}$ ) ('tandem' and 'alternating' configurations are after Pinyon et al. ${ }^{30}$ ). Comparison of the effect of array configuration on gene electrotransfer utilized a single electric pulse parameter set: $40 \mathrm{~V}, 10$ pulses, 50 ms duration, 1 pulse per second.

\section{Effect of pulse parameters on gene electrotransfer}

Voltage. Using the 'tandem' array configuration, the pulse parameters were $10 \mathrm{~V}, 20 \mathrm{~V}$ or $40 \mathrm{~V}, 10$ pulses, $40 \mathrm{~ms}$ pulse duration, 1 pulse per second ( $n=9$ per group).

Pulse number. Using the 'tandem' array configuration, the pulse was set at $10 \mathrm{~V}$ or $20 \mathrm{~V}$, pulse number ranging from 1 to $40(1,3,5,10,20$ and 40$)$, $40 \mathrm{~ms}$ pulse duration, 1 pulse per second ( $n=6$ per group, except for 5 pulses where $n=9$ ).

Pulse duration. Using the 'tandem' array configuration, the pulse was set at $40 \mathrm{~V}, 1$ or 5 pulses, and a range of pulse durations $(0.1-400 \mathrm{~ms})$, with appropriate gap durations to achieve 1 pulse per second (999.9-600 ms) ( $n=6$ per group).

Pulse separation. Using the 'Tandem' array configuration, the pulse was set at $40 \mathrm{~V}, 2$ or 5 pulses, $40 \mathrm{~ms}$ pulse duration, and a range of pulse separations (50, 100, 250, 500 and $1000 \mathrm{~ms})(n=3$ per 2 pulses group and $n=5$ per 5 pulses group).

\section{Evaluation of cell toxicity}

Using the tandem array configuration, a range of pulse profiles was used to assess cell toxicity ( $0-100 \mathrm{~V} ; 1-40$ pulses, 40 ms pulse duration, 1 pulse per second). The plasmid DNA in Tris-buffered saline was applied to the coverslip. Immediately after electroporation, coverslips were placed in a humidity chamber for $2 \mathrm{~min}$. Coverslips were then placed in fresh, warmed media, and returned to the incubator for $30 \mathrm{~min}$. Cell death was identified by propidium iodide fluorescence, where incubation with propidium iodide $\left(2 \mu \mathrm{g} \mathrm{ml}^{-1}\right)$ was undertaken for $5 \mathrm{~min}$ at $37^{\circ} \mathrm{C}$. Coverslips were washed in phosphate-buffered saline and fixed in PFA, before imaging using the confocal LSM (Helium-Neon laser, 633 nm excitation; emission 588-649 nm).

\section{Electric field mapping}

The electric field focusing produced by the five different cochlear implant electrode array configurations was mapped using a custom platinum electrode insulated to $\sim 300 \mu \mathrm{m}$ from the tip (SAFELEAD F-E2-24; Grass Technologies, Rockland, MA, USA), with an isolated voltage-following amplifier (Axopatch 200B; Axon Instruments, Molecular Devices, Sunnyvale, (A, USA) and a silver silver-chloride reference electrode (Figure 4a). Junction potentials were offset-adjusted to zero, and potentials were measured at the end of a $100 \mathrm{~ms} 4 \mathrm{~V}$ pulse applied to the array (Figure $4 \mathrm{~b}$ ). Below $\sim 2 \mathrm{~V}$, the potential decayed to zero as the platinum electrodes polarized (Figure $4 \mathrm{~b}$ ). From $\sim 3 \mathrm{~V}$, the quasi steady-state potential at $100 \mathrm{~ms}$ increased linearly with increasing applied voltage. Data were low-pass filtered at $1 \mathrm{kHz}$ and captured at $50 \mathrm{kHz}$ sampling rate using a Digidata 1440 interface (Axon Instruments). Data were analyzed using the Clampex Software (version 10.2.0.12; Axon Instruments). The voltage-sensing electrode was positioned relative to the electrode array using a translational stage (SliceScope Pro 6000; Scientifica, East Sussex, UK), and a 3D micromanipulator (ROE-200; Sutter Instrument Company,
Novato, CA, USA). Images were captured to map the location of the probe in relation to the electrode array using video imaging (Zeiss LSM710, $0.5 \times$ converter; MF cool ProgRes CCD camera and software; JENOPTIK, Jena, Germany). Constant voltage pulses were delivered to the electrode array using an analogue controlled isolated stimulator (Model 2200; AM Systems, Sequim, WA, USA).

\section{In vivo gene delivery}

Bionic array-based gene delivery of the GFP reporter plasmid DNA was undertaken in the normal hearing guinea pig cochlea. This followed the procedure outlined by Pinyon et al..$^{30}$ using coloured guinea pigs of both sexes 300-900 g in weight, following a UNSW Australia Animal Care and Ethics Committee approved protocol. No randomization or blinding was done for animal experiments. Six array-based gene delivery experiments were undertaken, along with two no-electroporation control experiments. These sample sizes were determined from the previous low background signals in controls; ${ }^{30}$ no statistical comparisons were undertaken for these experiments and no exclusion criteria were used. Under isoflurane anaesthesia, the plasmid DNA $\left(2 \mu \mathrm{g} \mathrm{\mu l} \mathrm{l}^{-1}\right.$ in Tris(hydroxymethyl)aminomethane (Tris) buffer) was delivered to the cochlea via the round window $(20 \mu \mathrm{l}$ in $40 \mathrm{~s}$ using a microdrive pump; Narashige IM-1, Narishige International USA, Inc., Amityville, NY, USA). The electrode array was then inserted into the basal turn scala tympani via the round window and $2 \times 100 \mathrm{~ms}$ pulses (10-15 V) were applied using the 'tandem' configuration. The array was removed after $2 \mathrm{~min}$, and the post-auricular surgical field was closed. The animals were killed after 1 week and following fixation with $4 \%$ paraformaldehyde, the nuclear-localized GFP reporter signal in the target mesenchymal cell area adjacent to the electrode array was visualized using confocal laser scanning microscopy (Zeiss NLO710 LSM, Jena, Germany; argon laser $488 \mathrm{~nm} \mathrm{~nm}$ excitation, 492-548 nm emission; background fluorescence was imaged using a $561-\mathrm{nm}$ diode pumped solid state laser, 564-690 nm emission).

\section{Statistical analyses}

Treatment effects were analyzed using ranked one- or two-way ANOVA with validation of normal distribution (Sigmaplot v.12.5; Systat Software, Inc., San Jose, CA, USA). Individual comparisons used Holm-Sidak multiple comparisons with alpha $=0.05$ for baseline statistical threshold; or ranked ANOVA with Tukey's test post hoc pairwise comparisons. Data are presented as mean \pm standard error of mean. Sample sizes are stated for each experiment within the Results section and Figure legends.

\section{CONFLICT OF INTEREST}

Three patent filings are associated with this research: (i) Title: Method of providing agents to the cochlea. Inventor: GD Housley. Filing status: National Phase Examination-Europe (application no. 10799287.7; filing date 5 July 2010), National Phase-United States (application no. 13/384020; filing date 5 July 2010). Assignee: NewSouth Innovations Pty Limited. (ii) Title: Method and apparatus for close-field electroporation. Inventor: GD Housley, M Klugmann, J Pinyon. Filing status: Provisional, Australia (application no. 2013902263; filed 21 June 2013). Assignee: NewSouth Innovations Pty Limited. (iii) Title: Electroporation system for controlled localized therapeutics delivery. Inventor: GD Housley, NH Lovell. Filing status: Australian Provisional Patent filing (application no. 2015902456; filing date 25 June 2015). Assignee: NewSouth Innovations Pty Limited.

\section{ACKNOWLEDGEMENTS}

Professor Gregg Suaning is thanked for discussion around electric field modelling. Funded by an Australian Research Council Discovery Grant (DP151014754).

\section{REFERENCES}

1 Satkauskas S, Bureau MF, Puc M, Mahfoudi A, Scherman D, Miklavcic D et al. Mechanisms of in vivo DNA electrotransfer: respective contributions of cell electropermeabilization and DNA electrophoresis. Mol Ther 2002; 5: 133-140.

2 Scherman D, Bigey P, Bureau MF. Applications of plasmid electrotransfer. Technol Cancer Res Treat 2002; 1: 351-354.

3 Guo H, Hao R, Wei Y, Sun D, Sun S, Zhang Z. Optimization of electrotransfection conditions of mammalian cells with different biological features. J Membr Biol 2012; 245: 789-795. 
4 Haberl S, Kanduser M, Flisar K, Hodzic D, Bregar VB, Miklavcic D et al. Effect of different parameters used for in vitro gene electrotransfer on gene expression efficiency, cell viability and visualization of plasmid DNA at the membrane level. J Gene Med 2013; 15: 169-181.

5 Miklavcic D, Mali B, Kos B, Heller R, Sersa G. Electrochemotherapy: from the drawing board into medical practice. Biomed Eng Online 2014; 13: 29.

6 Faurie C, Phez E, Golzio M, Vossen C, Lesbordes JC, Delteil C et al. Effect of electric field vectoriality on electrically mediated gene delivery in mammalian cells. Biochim Biophys Acta 2004; 1665: 92-100.

7 Phez E, Faurie C, Golzio M, Teissie J, Rols MP. New insights in the visualization of membrane permeabilization and DNA/membrane interaction of cells submitted to electric pulses. Biochim Biophys Acta 2005; 1724: 248-254.

8 Teissie J, Golzio M, Rols MP. Mechanisms of cell membrane electropermeabilization: a minireview of our present (lack of?) knowledge. Biochim Biophys Acta 2005; 1724: 270-280.

9 Rols MP. Electropermeabilization, a physical method for the delivery of therapeutic molecules into cells. Biochim Biophys Acta 2006; 1758: 423-428.

10 Xie TD, Tsong TY. Study of mechanisms of electric field-induced DNA transfection. V. Effects of DNA topology on surface binding, cell uptake, expression, and integration into host chromosomes of DNA in the mammalian cell. Biophys J 1993; 65: 1684-1689.

11 Klenchin VA, Sukharev SI, Serov SM, Chernomordik LV, Chizmadzhev Yu A. Electrically induced DNA uptake by cells is a fast process involving DNA electrophoresis. Biophys J 1991; 60: 804-811.

12 Sukharev SI, Klenchin VA, Serov SM, Chernomordik LV, Chizmadzhev Yu A. Electroporation and electrophoretic DNA transfer into cells. The effect of DNA interaction with electropores. Biophys J 1992; 63: 1320-1327.

13 Hristova NI, Tsoneva I, Neumann E. Sphingosine-mediated electroporative DNA transfer through lipid bilayers. FEBS Lett 1997; 415: 81-86.

14 Neumann E, Schaefer-Ridder M, Wang $\mathrm{Y}$, Hofschneider $\mathrm{PH}$. Gene transfer into mouse lyoma cells by electroporation in high electric fields. EMBO J 1982; 1: 841-845.

15 Heller LC, Ugen K, Heller R. Electroporation for targeted gene transfer. Expert Opin Drug Deliv 2005; 2: 255-268.

16 Rebersek M, Faurie C, Kanduser M, Corovic S, Teissie J, Rols MP et al. Electroporator with automatic change of electric field direction improves gene electrotransfer in-vitro. Biomed Eng Online 2007; 6: 25.

17 Jordan ET, Collins M, Terefe J, Ugozzoli L, Rubio T. Optimizing electroporation conditions in primary and other difficult-to-transfect cells. J Biomol Tech 2008; 19: 328-334.

18 Bertram B, Wiese S, von Holst A. High-efficiency transfection and survival rates of embryonic and adult mouse neural stem cells achieved by electroporation J Neurosci Methods 2012; 209: 420-427.

19 Odani N, Ito K, Nakamura H. Electroporation as an efficient method of gene transfer. Dev Growth Differ 2008; 50: 443-448.

20 Masuda M, Pak K, Chavez E, Ryan AF. TFE2 and GATA3 enhance induction of POU4F3 and myosin Vlla positive cells in nonsensory cochlear epithelium by ATOH1. Dev Biol 2012; 372: 68-80.

21 Driver EC, Kelley MW. Transfection of mouse cochlear explants by electroporation. Curr Protoc Neurosci 2010; Chapter 4(Unit 4): 1-10.

22 Mir LM. Nucleic acids electrotransfer-based gene therapy (electrogenetherapy): past, current, and future. Mol Biotechnol 2009; 43: 167-176.
23 Heller LC, Heller R. Electroporation gene therapy preclinical and clinical trials for melanoma. Curr Gene Ther 2010; 10: 312-317.

24 Mali B, Jarm T, Snoj M, Sersa G, Miklavcic D. Antitumor effectiveness of electrochemotherapy: a systematic review and meta-analysis. Eur J Surg Oncol 2013; 39: 4-16.

25 Haas K, Sin WC, Javaherian A, Li Z, Cline HT. Single-cell electroporation for gene transfer in vivo. Neuron 2001; 29: 583-591.

26 Rathenberg J, Nevian T, Witzemann V. High-efficiency transfection of individual neurons using modified electrophysiology techniques. J Neurosci Methods 2003; 126: $91-98$.

27 Ohmura N, Kawasaki K, Satoh T, Hata Y. In vivo electroporation to physiologically identified deep brain regions in postnatal mammals. Brain Struct Funct 2015; 220: 1307-1316.

28 Lin YC, Huang MY. Electroporation microchips for in vitro gene transfection. J Micromech Microeng 2001; 11: 542-547.

29 Chang WC, Sretavan DW. Single cell and neural process experimentation using laterally applied electrical fields between pairs of closely apposed microelectrodes with vertical sidewalls. Biosens Bioelectron 2009; 24: 3600-3607.

30 Pinyon JL, Tadros SF, Froud KE, AC YW, Tompson IT, Crawford EN et al. Close-field electroporation gene delivery using the cochlear implant electrode array enhances the bionic ear. Sci Transl Med 2014; 6: 233ra254.

31 Kranjc M, Markelc B, Bajd F, Cemazar M, Sersa I, Blagus T et al. In situ monitoring of electric field distribution in mouse tumor during electroporation. Radiology 2015; 274: $115-123$.

32 Nayerossadat N, Maedeh T, Ali PA. Viral and nonviral delivery systems for gene delivery. Adv Biomed Res 2012; 1: 27.

33 Zhou R, Norton JE, Zhang N, Dean DA. Electroporation-mediated transfer of plasmids to the lung results in reduced TLR9 signaling and inflammation. Gene Ther 2007; 14: 775-780.

34 Gehl J. Electroporation: theory and methds, perspectives for drug delivery, gene therapy and reserach. Acta Physiol Scand 1993; 177: 437-447.

35 LeWitt PA, Rezai AR, Leehey MA, Ojemann SG, Flaherty AW, Eskandar EN et al. AAV2-GAD gene therapy for advanced Parkinson's disease: a double-blind, sham-surgery controlled, randomised trial. Lancet Neurol 2011; 10: 309-319.

36 Muruve DA. The innate immune response to adenovirus vectors. Hum Gene Ther 2004; 15: 1157-1166.

37 Merrill DR, Bikson M, Jefferys JG. Electrical stimulation of excitable tissue: design of efficacious and safe protocols. J Neurosci Methods 2005; 141: 171-198.

38 Saulis G, Lape R, Praneviciute R, Mickevicius D. Changes of the solution pH due to exposure by high-voltage electric pulses. Bioelectrochemistry 2005; 67: 101-108.

39 Lacković I, Magjarević R, Miklavcic D. Three-dimensional finite-element analysis of Joule heating in electrochemotherapy and in vivo gene electrotransfer. IEEE Trans Dielectr Electr Insul 2009; 16: 1338-1347.

(i) $\Theta$ This work is licensed under a Creative Commons AttributionBY NC ND NonCommercial-NoDerivs 4.0 International License. The images or other third party material in this article are included in the article's Creative Commons license, unless indicated otherwise in the credit line; if the material is not included under the Creative Commons license, users will need to obtain permission from the license holder to reproduce the material. To view a copy of this license, visit http:// creativecommons.org/licenses/by-nc-nd/4.0/ 